\title{
AN ATTITUDE OF SUBCARPATHIAN'S RESIDENTS TO SUSTAINABLE SOLUTIONS FOR URBAN TRANSPORT
}

\author{
Dominik Zimon ${ }^{1, *}$ \\ ${ }^{1}$ Rzeszow University of Technology, Department of Management Systems and Logistics, Rzeszow, \\ Poland \\ ${ }^{*}$ Corresponding author: zdomin@prz.edu.pl
}

Keywords: Sustainable development; Urban transport; Sustainable solutions; Intelligent public transport.

\begin{abstract}
Sustainable development is a concept that appears more frequently in the context of urbanized cities. Rational management of city logistics and urban population change of consciousness becomes a priority. The purpose of this publication is to emphasize the need for changes in city logistics, to characterize the concept of sustainable transport and to present the results of research on: the views of residents of Podkarpacie on choosing alternatives to the car, and urban transport concept. The research process was conducted in two stages. The first stage of the research was conducted in 2014 within its scope included the study compared the inhabitants of Podkarpacie to sustainable forms of transport. The second stage of the study carried out in 2015 was designed to examine whether the implementation of Intelligent Public Transport Management System, has changed the ratio of respondents to sustainable transport.
\end{abstract}

\section{INTRODUCTION}

According to a report, published in 2014 by the University of Cambridge, "Climate change: Implications for Transport", greenhouse gas emissions from the transport sector have more than doubled since 1970, increasing to the equivalent of 7 billion tonnes of carbon dioxide (CO2eq) in 2010 and rising at a faster rate than for any other energy end-use sector. Around $80 \%$ of the increase is from road vehicles. Light vehicle ownership stands at 1 billion and is projected to double in the next few decades, with two-thirds of the growth in non- OECD countries. Around a tenth of the global population accounts for $80 \%$ of total motorised passenger kilometres, indicating that without stringent policy intervention that incentivises low-carbon transport options, economic growth will bring large increases in carbon emissions [1]. Decoupling transport from GDP growth is possible but will require the development and deployment of appropriate measures, advanced technologies and improved infrastructure. The cost-effectiveness of these opportunities may vary by region and over time. Delivering mitigation actions in the short-term could avoid lock-in effects resulting from the slow turnover of stock (particularly aircraft, trains and ships) and the long-life and sunk costs of infrastructure already in place. When developing low-carbon transport systems, behavioural change and infrastructure investments are often as important as developing more efficient vehicle technologies and using lower carbon fuels [2].

The concept of sustainability emerged and started to be developed because of the perceived imbalance of regional and local ecosystems. The imbalance was initially limited to particular geographical areas, but over time it has turned into a global problem affecting most regions in the world [3].

Sustainable development is an attempt at formulating a program which would integrate the different dimensions of human activity on the basis of a moral reflection as to human responsibility for nature. The sustainable development concept anticipates major civilisational change on the ecological, social and economic levels [4]. Zairi [5] says, that sustainable development is based on a perceived need to address environmental deterioration and to maintain the vital functions of natural systems for the well being of present and future generations. Sustainability is defined as 'the ability of an organization to adopt to change in the business environment to capture contemporary best practice methods and to achieve and maintain superior competitive performance. Although the basic 
idea of sustainable development is shared by all, its interpretation and applications tend to diverge in the various contexts that can be found. In logistics and goods transport, sustainability is related to taking the main elements into account [6]:

- The economic viability of logistics systems, which can mainly take place to the notion of Supply Chain Management (SCM).

- Respect for the environment, seen as an opportunity rather than a constraint, in the perspectives of Green SCM.

- Last but not least, the social and societal implications of logistics in a Social SCM approach [7].

Sustainable development is a concept that appears more frequently in the context of urbanized cities. Eighty percent of European Union citizens live in these cities, where majority of environmental and social problems are associated with transportation. "Congestion, poor air quality and noise are the biggest problems in the cities. Urban transport is responsible for about a quarter of $\mathrm{CO} 2$ emissions from transport in general. $69 \%$ of road accidents occur in the cities. Currently, the biggest problem in urban transportation is the imbalance in the areas of environmental and social aspects [8]. Consequently, the cost of providing transportation that meets the residents need is very high. Noise, illness, congestion, air pollution, lack of liquidity and safety are some of the externalities generated by the of modern urban transport systems [9]. As a result of the traffic jams, alone, the European economy loses every year nearly 100 billion euros, or $1 \%$ of EU GDP.

Rational management of city logistics and urban population change of consciousness becomes a priority [10]. According to the authors, the most important task of sustainable urban transport seems to be stimulation of sustainable demand for transport and to promote the concept of ecotravel [11,12]. For this purpose, the system must reach out for support measures to rationalize the use of vehicles, among which special attention ought to be focus on: carpooling, multimodal ways to travel through the cities, integrating individual transport and public transport to the city with included concepts of park \& ride, kiss \& ride and bike ride. Proper selection of these concepts and their adaptation to the realities of specific cities should greatly improve communication in the city, also reduce the size of the transport congestion and counteract current fashion for the use of private cars.

The problem with implementing the mentioned concepts is a change in mindset of society [13]. The starting point is to educate the people of the cities that the environment in which they live continues to deteriorate, therefore changing habits and target the sustainable development philosophy seems to be indispensable.

The purpose of this publication is to emphasize the need for changes in city logistics, to characterize the concept of sustainable transport and to present the results of research on: the views of residents of Podkarpacie on choosing alternatives to the car, and urban transport concept. The research process was conducted in two stages. The first stage of the research was conducted in 2014 within its scope included the study compared the inhabitants of Podkarpacie to sustainable forms of transport. The second stage of the study carried out in 2015 was designed to examine whether the implementation of Intelligent Public Transport Management System, has changed the ratio of respondents to sustainable transport.

\section{CHARACTERISTICS OF THE CONCEPT OF SUSTAINABLE URBAN TRANSPORT- LITERATURE REVIEW}

Sustainable urban transport should be based on Modal shifts. Modal shifts in transport involve shifting passengers and freight to lower-carbon forms of transport, for example from private vehicles to mass transit systems, from cars to bicycles, or from air to rail. Prioritising infrastructure for pedestrians and promoting non-motorised transit options create economic and social co-benefits. Barriers to modal shifts include social norms, existing urban form and the need for new infrastructure with high upfront costs, for example to build electric vehicle charging infrastructure or railways. Such costs may diminish after including co-benefits. 


\section{Park \& ride}

The concept of Park \& Ride is an infrastructure solution that is designed to encourage users of private cars and motorcycles to limit their use when traveling in cities. This program is about building parking for cars and motorcycles in the environment at major stops or suburban railway station, tram, metro or bus (operating on separate, collision-free lanes of traffic) and encouraging motorists to leave their private cars on the parking to use local public transport for trips within the city. After arriving and leaving the vehicle in the parking lot, traveling by public transport moves on privileged terms. A driver, who leaves his /her vehicle on 'park and ride' parking lot, can use a parking ticket on all public transport systems. In addition, that avoids a nuisance of seeking a parking space in the city center and saves on relatively high parking costs.

The organization of this type of urban travel system is closely linked with the use public transport, due to the need for availability. Well-designed park \& ride integration point should take account of [14]:

- compensation for delays,

- to provide an unidirectional or multidirectional interchange assurance,

- to minimize the time interchange through the use of short, safe and convenient move sections between stations, as well as pedestrian routes between parking lot-bus/train stops,

- appropriate, for the agglomeration, number of lines needed to communicate and to provide the frequency of running vehicles, so as to reach the downtown at different times of the day,

- to ensure the best possible visibility for drivers and pedestrians in areas where commuters' transfers take place.

The research, which was conducted in the UK in the cities of Cambridge, Brighton, Coventry, Plymouth, Norwich, Reading, York and Shrewsbury, which are shown in the Atkins report indicates that despite the fact that drivers often have to detour and change the route, it implementation of park and ride resulted in lower traffic congestion in the centers of these cities.

To function properly and fulfill its role implemented concept must be accompanied by proper number of parking spaces, and a very good accessibility to public transport, identified with a dense network of transport in regions with reduced entry for individual vehicle users. It should also ensure a sufficiently high quality of services provided by public transport. There are many benefits of implementation of the system. The most significant ones are: to increase security in moving around the center, to improve the quality of the environment, to eliminate unnecessary transport vehicle or noise reduction.

Park \& Ride system is known in Europe for approximately 60 years. It functions in a great success in Amsterdam, Hamburg, still thrives in Warsaw. Cologne offers 5570 free parking spots while in Berlin there are 4947 free ones. In Munich around for existing 7128 spaces, 1000 is free and available for Park \& Ride commuters. In the framework of that system, Rome has 31 parking lots, that can accommodate 13,000 cars. Moreover, Paris has to offer 547 car parks in a total number of about 100 thousand parking spaces.

The positive sides of Park \& Ride system are noticed also by Li et al., [15] claiming that P\&R schemes have been widely recognized as an effective means of addressing traffic congestion problems in densely developed urban areas. These schemes are used as a tool to encourage commuters to undertake their journeys in two parts: first driving a private car to a car park near transit stations and then completing the remainder of the journey by taking a transit mode. Successes of the P\&R schemes operating in European and U.S. cities have shown that the P\&R is a viable and promising travel demand management.

It ought to be noted, however, that some researchers remain sceptical about the affect that system Park \& Ride has on the environment. According to Meek et al., [16] P\&R increases the total distance travelled by some of its users, which in turn infers that there is also doubt that P\&R will universally reduce transport-related emissions. This is mainly because of low load factors on highfrequency dedicated buses but there are also increases in mileage from trips previously taken on public transport alone, and those that are newly generated or diverted from other centres. Because $\mathrm{P} \& \mathrm{R}$ attracts a significant proportion of these 'non-target' users the offsetting effect on reductions 
in car use may be considerable, although these trips have not yet been included in assessments of P\&R-induced mileage change. The potential environmental role of P\&R is also lessened somewhat by the technological advancements resulting in reductions in noxious emissions from the car fleet which have not been seen in buses.

\section{Bike \& ride}

Poles have about 9 million bicycles, however, in big cities, cycling still is from 1 to $3 \%$ of all the trips made by commuters. For comparison, in some European cities, travel bike share exceeds $30 \%$ (Copenhagen, Munster, Delft). Therefore, every conception of promoting cycling is very important. Bike \& Ride concept requires much less expenditure on infrastructure than Park \& Ride. It is also directed to another group of people. This system is to promote bike use among urban areas. Special parking is created for bicycles and mopeds, conveniently located in the vicinity of interchanges and major bus stops, similarly to Park \& Ride model. Once you reach the bicycle parking lot by bike, you can leave it on a privileged basis, and then continue your journey by public transport. The system can also be expanded to possibility of taking a bicycle with you to public transport and travel with it around the city. Some cities implement a management system which allows you to store the bicycle for a charge. Recently, the system also allows you to travel with your bike on subway trains. The implementation of the concept has a high degree of success especially in the cities with lower spatial development, where access to the parking lot does not consume a lot of time. The system is also well adopted in communities where access by bike to work is not recognized as discomfort or extravagance (Denmark, the Netherlands). The expansion of Bike \& Ride system, in cities, increases the use of bicycles in everyday life of the people and is beneficial for the urban environment and other road users.

Bike \& Ride park stations do not exclude the existence of Park \& Ride parking. Such a solution exists in Helsinki, where bicycle parking serve as bike rental for commuters traveling to the city by car [17]. The concept was also implemented in Warsaw, where each year the system expands through building another covered parking for bicycles (Połczyńska, Miłocińska and Wilanów stations). Moreover, growing number of emerging bicycle racks is equipped with a modern system of opening and closing with the use of Warsaw City Card. Method Bike \& Ride also works well in many cities in the world (Chicago, Toronto, Brampton) and Wroclaw.

The Dutch experience shows that bicycle use in access trips can be promoted by simply providing sufficient and attractive bicycle parking facilities [18]. Obviously, the availability of safe bicycle routes in the Netherlands makes it easier to limit the attention to various types of parking facilities. But the fact that travelers did not use bike-and-ride before the placement of parking facilities despite the availability of safe routes, suggests that cities and towns with more than negligible levels of bicycle ridership could also promote bike-and-ride by simply improving bicycle parking facilities at key stations and stops. The success of the Dutch experiments even seems to suggest that the barriers for changing travel behavior in access trips may be substantially lower than those that prevent overall mode change perhaps because public transport users are confronted everyday with the relative inconvenience of access trips. In addition, the 'conformity and peer' effect may be at work here once bicycle parking facilities are available and the first travelers start making use of it, others will follow. With some caution, this may suggest that the promotion of bicycle use in access trips may help to increase bicycle ridership in general, by introducing the bicycle as a means of everyday travel to new groups of travelers. The Dutch experience shows that improvements in bicycle parking can especially have an impact at stations with high passenger numbers, high shares of commuters and students, and relatively high densities in an area of $3-4 \mathrm{~km}$ around the station [19].

\section{Carpooling}

Carpooling is one method of traveling in groups. The idea of it is based on mutual agreement between the users of the system - drivers, who have their private or business cars, allowing space in their vehicles, and the passenger or passengers who have ordered the use of the seat. In other words, 
you can share your vehicle seats with those who want to get to the same destination at the same time. The owner of a car obtains compensation from passengers for part of the operating costs of vehicles. At the same time, passengers save money for the amount they would have spent on an individual travel expanse by car, taxi or even, in some cases, urban public transport ticket. Correia and Viegas [20] state that carpooling, despite being a simple concept which could at a first look be a very effective measure for decreasing urban congestion, has not been able to produce significant results in other cities, and the outlook in the Lisbon region does not seem more promising. The carpooling club scheme was not perceived as providing more benefits of flexibility than the inconvenience of travelling with people outside the household. Nevertheless, it continues to appeal to certain social groups due to economics or their more open attitudes and for these, the club may represent an interesting platform for meeting other carpoolers.

Travelers, in accordance with the concept of a common group trips, can make use of one car or rotation of several vehicles belonging to several owners. This system has many advantages [21]:

- reduces expenditure on travel for its users, as well as, in some cases, significantly reduces travel time through the use of specifically dedicated for car-sharing participants transit lanes,

- reduces emissions, noise, congestion, transport size and the number of vehicles in circulation, also improves the environment and offers a choice mode of travel for the local community,

- optimizes the use of on-site parking for employees commuting to work every day, brings them closer together, improves the image of the company and reduces stress, which is associated with commuting.

Despite indications of some advantages, traveling in the car pooling system also experience few disadvantages associated with such method of commuting:

- inability to do shopping and attend to personal matters during the trip

- frequent change of route due to high rotation of travelers especially where there are no assigned pick up points,

- additional mental load laid on driver, responsibility that results from carrying passengers and their safety.

\section{PODKARPACIE POPULATION'S ATTITUDE TOWARD THE CONCEPT OF SUSTAINABLE TRANSPORT - PRESENTATION OF RESEARCH RESULTS}

The main purpose of the research process was to identify the factors that influence the decision on choosing means of transport other than public transport for trips within the city of Rzeszow. The specific objective was to get to know the opinion of private car drivers, cyclists and commuters regarding possible ways of solving the challenges of urban transport by introducing solutions in the field of sustainable development. The research tool was a questionnaire consisting of 20 questions of which there were both open and closed questions. The asked respondent's questions were not accidental, and each of them had a specific objective and equally affected the final outcome of the study. The survey was conducted in June 2014 on weekdays, in the morning and afternoon hours in suitable for that purpose places in Rzeszów. Of the 300 respondents, 165 were males (55\%) and 135 females (45\%). The study was carried out before the the implementation of the Public Transport Management System (which will be characterized in the further part the article).

Based on the research process, it was found that:

- The vast majority of respondents have a car at their place of residence. Most respondents (71\%) indicated that they have 1 car, while $15 \%$ indicated that they have more than two cars; as many as $14 \%$ of the respondents did not indicate its ownership. The main reasons for the use of a car in moving around the city, respondents answered: driving comfort, the ability to decide on the route, safety and speed. The research carried out in Austria shows that the main rationale use of cars is a sense of freedom and independence, as well as fulfilling dreams. 
- Most often chosen by respondents means of transport in the city is the bus. The answer to that indicated $52 \%$ of respondents. The second, in turn, the most popular means of transport is a car that is chosen by $38 \%$ of respondents. Only $9 \%$ of respondents most often moves around the city by bike, and $1 \%$ indicated other than the above means of transport. This situation may result from the increasing popularity of urban public transport in Rzeszow, improve the quality of its services (purchase of new, air-conditioned buses and discard the oldest, more than 30year-old vehicles, the opportunity to purchase tickets through the mobile application, work on updating schedules and the creation of new routes) and increasing the capacity of the main streets in the city after their remodel and thus greater confidence that the bus will reach its destination within the scheduled time even during high congestion caused by various events. Comparing the most frequently chosen means of communication with the concluded in the previous question, about the number of car ownership in the place of residence, it should be noted that despite the fact that the respondents have at least one car, it would often choose the bus as a means of transport to move around the city of Rzeszow.

- When asked about the use of bicycles as a mode of transport in commuting to work, school or college, only $9 \%$ of respondents answered in the affirmative. The vast majority of respondents (91\%) denied using the bicycle as a mode of transport in this type of travel. The main reasons to use the bike the respondents point out: economic factors, increased environmental awareness, positive impact on health. On the other hand, the lack of use of the bicycle was greatly affected by the following: large distance, lack of comfort, the possibility of theft, an insufficient number of bicycle paths, specific occupation, low security, and longer travel time.

- In summary indicated determinants of use and non-use bicycle commuting to work, school or college, can be divided into the following criteria: psychological - due to the long-standing habits of respondents, having a base in their mentality and tastes; distances - near / far, faster / slower; changing decision may be only due to change of residence or travel destination; safety depends only on administrative authority; economic - not all afford to buy a bicycle, just as not all afford to commute by car or public transport.

- Of the 300 respondents, asked about factors that could affect the abandonment of private transport to alternative means of transport, the factors that were most frequently indicated are: to save on the cost of fuel (91 respondents), high frequency of departures by public transport means (66 respondents), to declare that one car trip a few people reduce congestion on the roads (37 respondents), and free wireless Internet access in public transport and at bus stops (31 respondents). Other proposed answers received much less support.

- A study shows that only 25 respondents pointed to environmental performance as a determinant of increased interest in public transport, while 14 - improving the quality of passenger information in the means of public transport and at bus stops. Possibility of taking the bike to the center of public transport, as well as free parking for cars located in close proximity to bus stops have been indicated by the 17 respondents, while improving the integration of public transport was indicated 15 times. Least, only 4 times, respondents indicated, access to current information from the country and the world in public transport and at bus stops.

- For questions regarding the effectiveness of the implementation Rzeszow Bike \& Ride system, the number of supporters and opponents is more or less comparable. For $43 \%$ of respondents, such a system is beneficial and desired in Rzeszow, while according to $41 \%$, such investment is not needed. In this respect, as much as $16 \%$ of respondents have no opinion.

- Studies show that as many as $75 \%$ of respondents at least some of the time uses the method of carpooling and would agree to make available free space in their car or have used a seat in other user's car in commuting to work, school, or university. On the other hand, $18 \%$ of respondents did not consider this method as safe and recommendable, and 7\% did not have a clear opinion, they have never considered such transportation method. 


\section{ANALYSIS AND EVALUATION OF THE IMPLEMENTATION OF INTELLIGENT PUBLIC TRANSPORT MANAGEMENT SYSTEM}

The authorities of the city of Rzeszow trying to promote sustainable forms of urban transport have decided to implement the Integrated Traffic Management System and Public Transport. The system became operational in the first months of 2015. This system integrates two elements namely area traffic control system Road and Public Transport Management System. The subject of research and analysis will be Public Transport Management System, which enables the identification of the location of vehicles, counting the number of passengers and control quality standards of passenger service by operators. These actions allow to improve the quality of public transport by an adjustment to the timetable, the reconstruction of the road system and verification of control algorithms, etc.

The premise of the implemented system was more fully adapt to the needs of the residents of the city and increase the quality of services by streamlining areas such as:

- The route planning,

- Control of punctuality

- Personnel management and fleet

In carrying out these tasks system operators have at their disposal specialized modules by which they can track the movement of vehicles, to make modification and keep passengers informed of the exact hours of courses (Fig. 1).

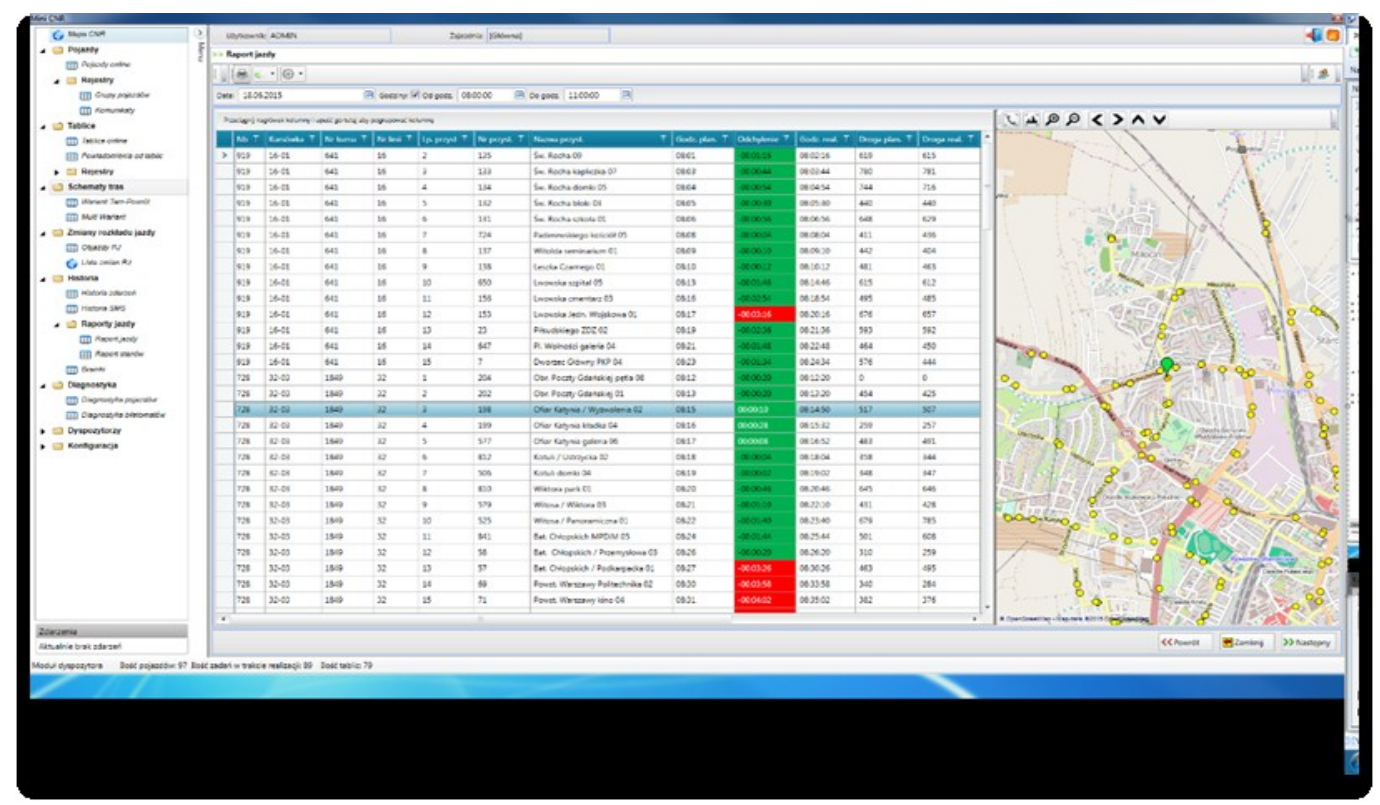

Fig 1. A sample screenshot of vehicle fleet management

Filtered data on specific vehicles can be presented in various forms by separate program modules (Fig. 2). 


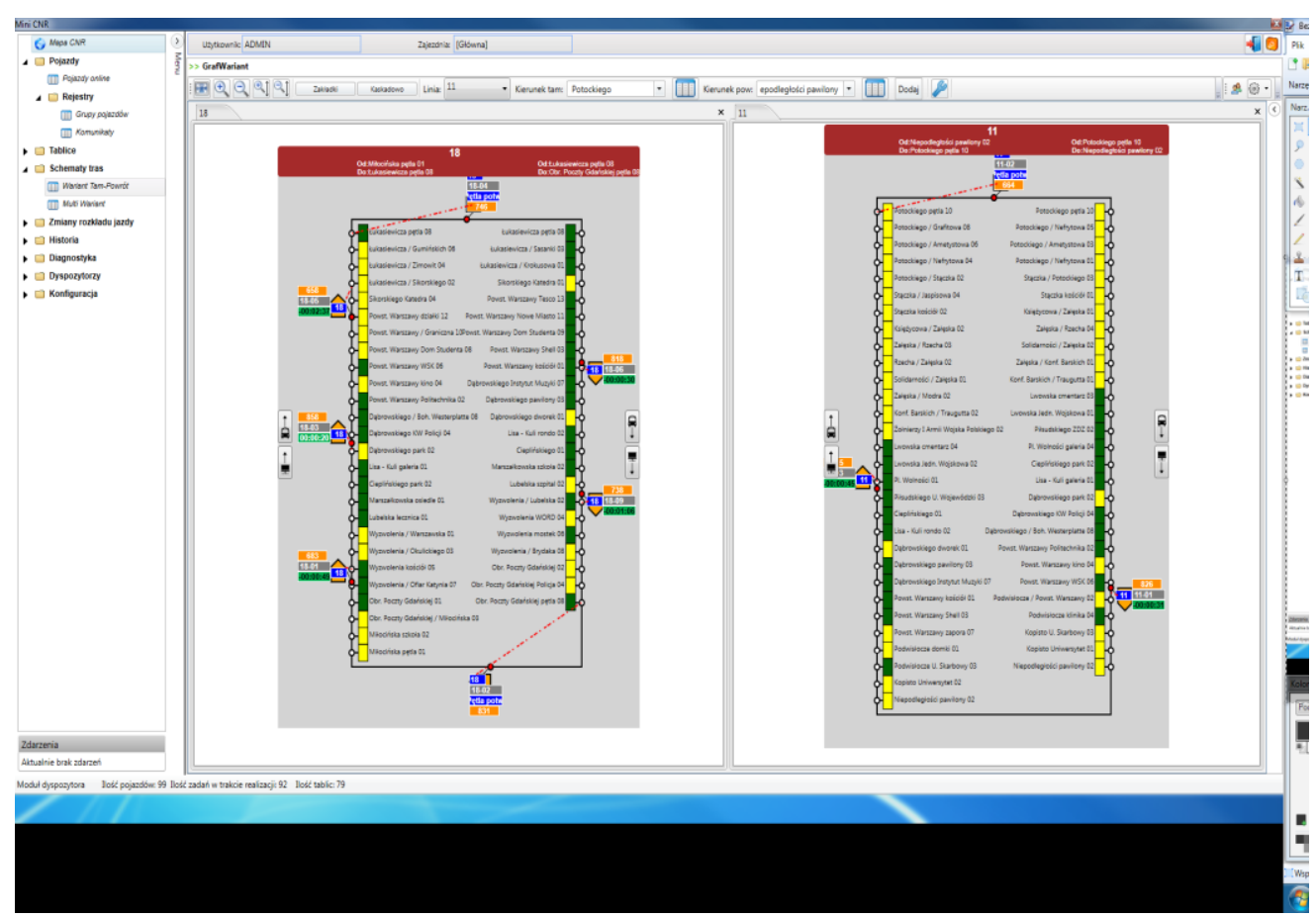

Fig 2. Filtering data about the vehicles

The system also has a module that allows you to analyze timeliness of any vehicle. It allows to determine the departure of the stop in a real-time, for each of the lines available in the database and for each bus. Any time differences that occur during the course, are determined by the on-board computer of the vehicle. Tools that are in this module allow for tabular and graphical presentation of punctuality with filtering capabilities (Fig 3).

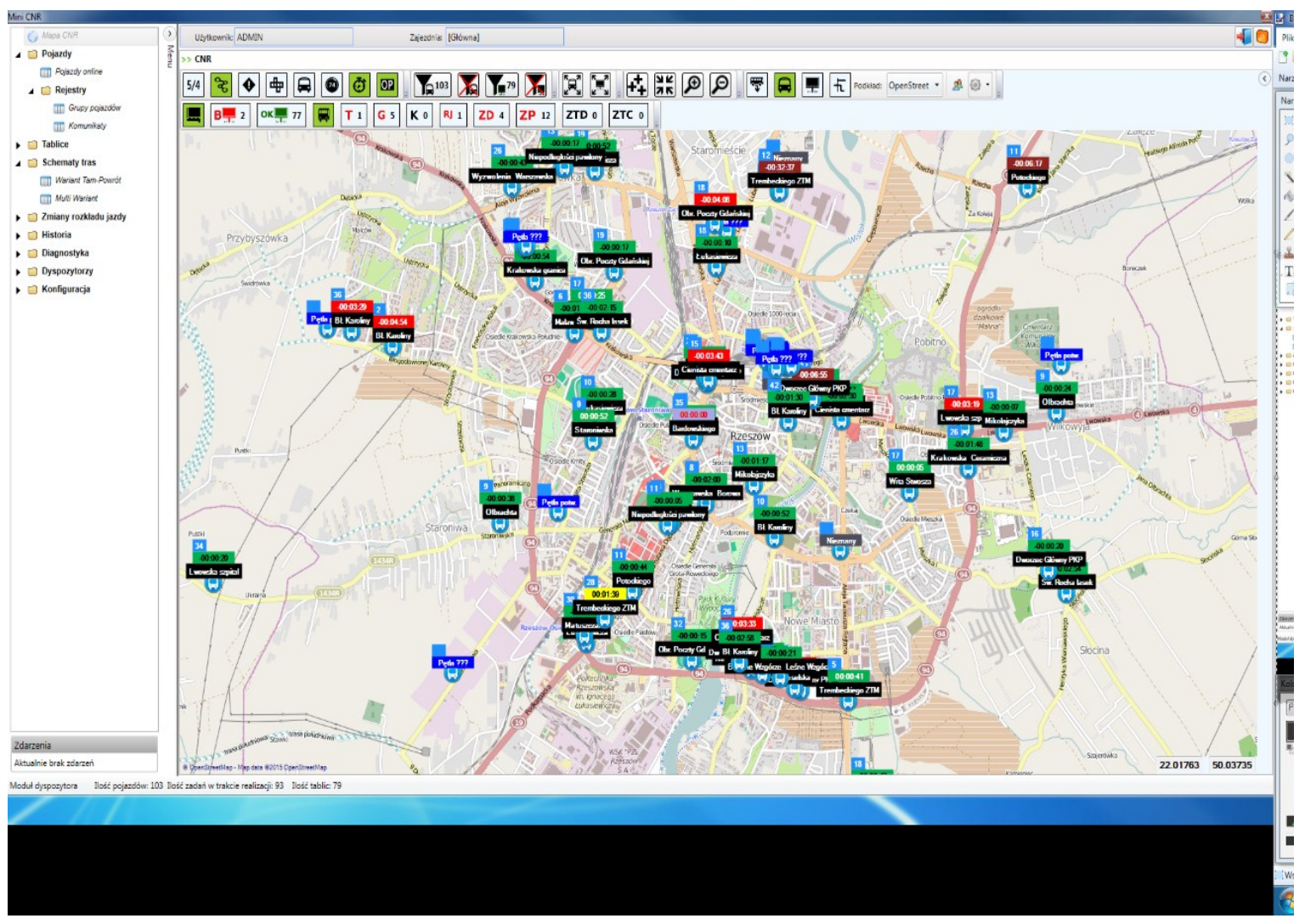

Fig 3. Filtering information regarding a specific course 
It is worth noting that in the framework of the implemented system an infrastructure was also developed: vehicles were equipped with on-board computers and inside information sign board. Bus stops have been modernized and equipped with an array of date updated from timetables.

The main aim of this chapet was to determine whether the Public Transport Management System meets the expectations of residents of Podkarpacie. The research process was conducted in June 2015, three months after the implementation of the Public Transport Management System.Of the 300 respondents, 144 were males (48\%) and 156 females $(52 \%)$. Based on the research process, it was found that:

- Still most often chosen means of transport is the bus. That answer was declared by $59 \%$ of respondents. Comparing these results with studies of last year, we can say that there was a slight (7\%) increase in interest in public transport.

- Respondents in the majority (73\%) positively evaluate the changes resulting from the implementation of the Public Transport Management System. Respondents emphasized that the implementation of the system can help to increase the use of buses in urban travel.

- $64 \%$ of respondents said that since the implementation of the system punctuality of buses has significantly increased.

- $4 \%$ of respondents declared that they did not use public transport for many years, and only because of the implementation of the new system decided to choose this means of transport.

- $\quad 27 \%$ of respondents declared that thanks to the facilities resulting from the implementation of the system they will more frequently choose the bus as a means of transportation.

- Over $80 \%$ of respondents described the investment in the development of public transport management system as a needed.

- $\quad$ Passengers very positively evaluate current level of modernization of public transport in the city, and the new passenger information system significantly affect its improvement. Almost every aspect of the technical side of the E-INFO evaluated in a positive way.

\section{DISCUSSION}

In summary, according to the authors of multimodal systems, preferably in Rzeszow would be Bike \& Ride system. This is due to the fact that Rzeszów is a relatively small city and has an extensive network of bicycle paths. City authorities' actions should be aimed at promoting this mode of transport (also during commuting) [22]. Furthermore, in order to increase the popularity of cycling journey, the city would primarily have to create storage, covered, fenced and monitored 24/7 rental spaces. This would significantly increase the risk of theft or destruction of vehicles. There is also need for further investments in new bike lanes, modernization of current ones, improving safety in road intersections, building special locks for cyclists at intersections with traffic signal lights [23]. Of course, the seasonality of this solution has to be taken into account; moreover, studies show that the bike is mainly selected for leisure travel and social activity. Occasionally, respondents choose this mode of transport for trips associated with maintaining the home and work.

Method Park \& Ride indicated by $73 \%$ of respondents as an effective, but it is not suitable for Rzeszow at the moment, as Rzeszow is too small. Park \& Ride sites operate in Krakow and Warsaw, where they are not utilized as planned. This of course does not question the design and simulation, because such parking may be necessary in the near future. Still only if neighboring cities like Boguchwała, Świlcza, Tyczyn would join Rzeszow in creating Park \& Ride system. Possible location of the Park \& Ride along the border zones of privileged for public transport and private is presented on Fig 4. 


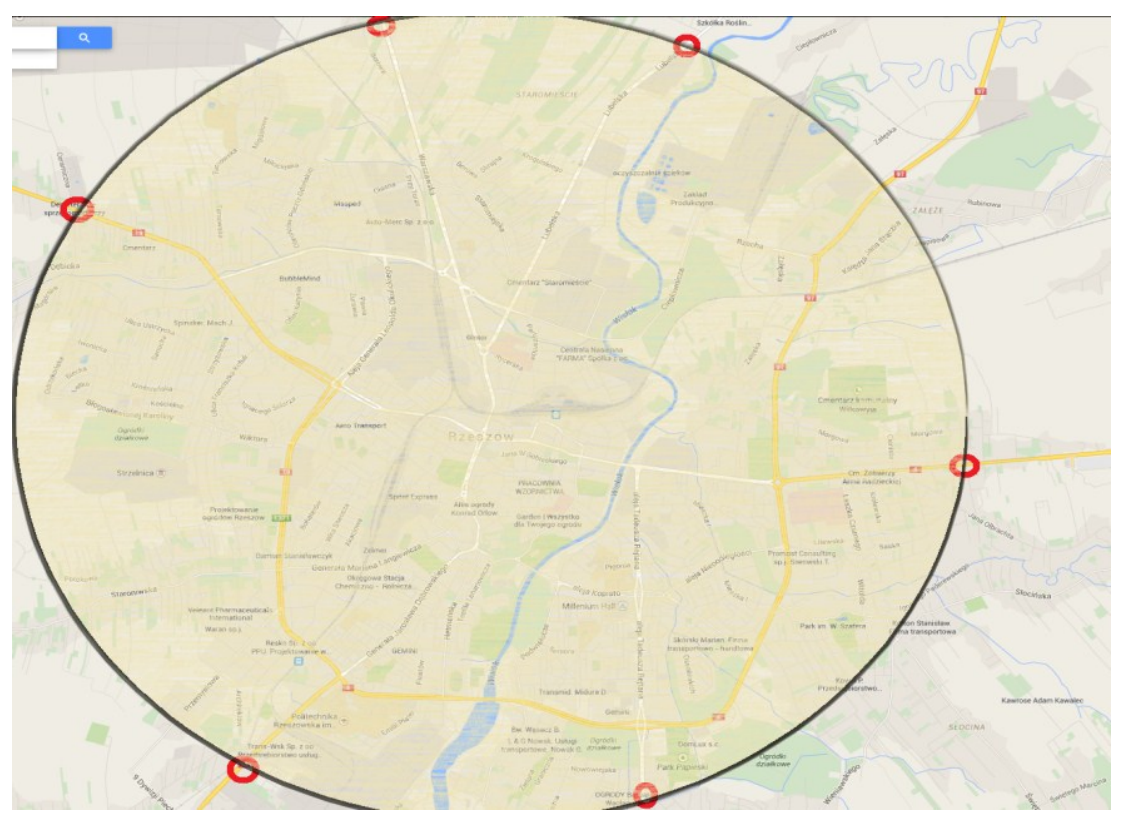

Fig 4. Possible location of the Park \& Ride

Implementation of Intelligent Public Transport Management System has not led to significant results but was met with appreciation of the respondents. The main advantages of the system may include a slight increase in interest in public transport and a significant increase in the quality of services provided. The increase in the quality of services can be considered as a very important element of pro-ecological strategy. The constant increase in the quality of services provided today is a necessity to increase interest in public transport, this thesis is confirmed by the results of research conducted by Dell'Olio et al., [24], Radnovića et al., [25] and Gajewską and Grigoroudis [26].

To improve the popularity of public transport, besides the designation of a specially privileged area for buses, ticket prices should be reduced. Increase in accessibility to public transportation, especially for passengers of large residential areas (ie. Commuter towns) and neighboring villages would be crucial. If residents of these areas have very easy access to the rest of the city and jobs mainly located outside the city limits, in the economic zones they would use urban transport, even if the only reason to do so be saving on fuel cost.

\section{CONCLUSIONS}

Sustainable urban transport is a current and complex problem. On one hand, there is a need for improving the logistics activities of companies operating within the cities and caring for the comfort of people living in the city. On the other, city council should be focused on environmental activities. As a result, implementation of activities directed toward sustainable urban transport is a major challenge for policy makers, business actors and civil society because of a compromise between the initial cost and long-term profits. There is no doubt that the change in mindset of society will be a long and difficult process; the selection of ecological solutions requires some sacrifices and changes in practices but in the future will result in the creation of environmentally and human friendly cities. According to the authors to promote greener ways of travel concept requires investment in the enhancement of urban public transport (transport telematics, optimization runs, investment in infrastructure). Furthermore, to improve the concept of urban bike paths and investments in secure bicycle parking, and focus on facilitation within the concept of carpooling. Survey results seem to confirm this thesis. Analysis of the results allowed the following conclusions:

- Residents of Rzeszów decide on the choice of means of transport mainly for economic reasons. Ecology is in the background. 
- Residents of the city lack of ecological knowledge and awareness, therefore the solutions proposed in the publication should be preceded by a broad social campaign focused on the importance of ecology and promotion of a healthy lifestyle.

- Bicycles for most of the residents are used for recreation or sport; only occasionally it is a means of transportation used to move around the city.

- Residents of Rzeszow are divided when it comes to the implementation of multimodal transport systems. However, more than half of them are positive about the proposed systems. According to the authors, it is a good omen for the future. Consequently, this is the right time, for the city authorities, to promote sustainable transport which in a few years would lead to successful implementation of the concepts described in the publication.

- Implementation of the Public Transport Management System can be considered a good investment, which over time will affect the growth of interest in public transport.

- Residents of Rzeszow speak very positively about the newly implemented Public Transport Management System.

- The newly implemented system has contributed to the significant improvement in the quality of services.

- There is a lack of appropriate pricing signals, which may change transport preferences of residents in the city.

- Research shows that a person choosing a private car, quite often cannot justify the expediency of this choice in the context of a bike or public transport.

The choice of means of transport is dependent on a number of qualitative factors. Evaluation of the different modes of transport for these factors is made subjectively by each traveler. Therefore, the primary task of sustainable urban transport is the development of such qualities and characteristics of sustainable travel concept, which would affect decision process when choosing an environmentally friendly means of transportation. It is not an easy task, the main problem in the development of sustainable urban transport is a need to involve a significant number of stakeholders to make the necessary breakthroughs in research and development. Another issue is to develop and implement appropriate policies to encourage, motivate, and if necessary make provisions to ensure use in the future schemes aimed at sustainable development. According to the authors, investments in sustainable logistics are inevitable over time as technology changes the consciousness of a society that is more aware and ready for new ideas and solutions.

\section{References}

[1] Grema, L. U., Abubakar, A. B., \& Obiukwu, O. O. (2013). Carbon emission control measures. International Letters of Natural Sciences Vol. 3 (2013) pp 21-27

[2] Rao, C., Goh, M., Zhao, Y., \& Zheng, J. (2015). Location selection of city logistics centers under sustainability. Transportation Research Part D: Transport and Environment, 36, 29-44.

[3] Dasaklis TK, Pappis CP. Supply chain management in view of climate change: an overview of possible impacts and the road ahead. Journal of Industrial Engineering and Management. 2013;6(4): 1139-1161.

[4] Pawłowski A. The sustainable development revolution. Problems of sustainable development. 2009;4(1): 65-76.

[5] Zairi M. Beyond TQM implementation: the new paradigm of TQM sustainability, Total Quality Management, 2002;13(8): 1161-1172.

[6] Gonzalez-Feliu, J., \& Morana, J. (2014). Assessing urban logistics pooling sustainability via a hierarchic dashboard from a group decision perspective. Sustainable Logistics. Emerald Group Publishing, series: Transport and Sustainability, (6), 113-135.

[7] Morana, J. (2013). Sustainable supply chain management. IST Wiley. 
[8] Anderson, S., Allen, J., \& Browne, M. (2005). Urban logistics-how can it meet policy makers' sustainability objectives?. Journal of Transport Geography, 13(1), 71-81.

[9] Lindholm, M. (2013), Urban freight transport from a local authority perspective - a literature review, EuropeanTransport , Vol. 54 (3), pp. 1-37.

[10] Mutingi, M. Developing green supply chain management strategies: A taxonomic approach. Journal of Industrial Engineering and Management. 2013;6(2): 525-546.

[11] Banister, D. (2008). The sustainable mobility paradigm. Transport Policy, 15(2), 73-80.

[12] Page, M. (2005). Non-motorized transportation policy. Handbooks in transport (pp. 6)

[13] Rajovic, G., \& Bulatovic, J. (2015). State of environmental awareness in northeastern Montenegro: a review, International Letters of Natural Sciences Vol. 29 (2015) pp 43-56

[14] Molecki B, Morel O. Uwarunkowania ruchowe organizacji przesiadek w transporcie zbiorowym. Transport Miejski, 2003;12: 26-33.

[15] Li ZC, Lam WH, Wong SC, Zhu DL, Huang HJ. Modeling park-and-ride services in a multimodal transport network with elastic demand. Transportation Research Record: Journal of the Transportation Research Board. 1994;1: 101-109.

[16] Meek S, Ison S, Enoch M. Role of Bus-Based Park and Ride in the UK: A Temporal and Evaluative Review. Transport Reviews. 2008;28(6): 781-803.

[17] Szymczak M. Logistyka miejska. Poznań: Wydawnictwo Akademii Ekonomicznej w Poznaniu; 2008.

[18] Maes, J., \& Vanelslander, T. (2012). The use of bicycle messengers in the logistics chain, concepts further revised. Procedia-Social and Behavioral Sciences, 39, 409-423.

[19] Martens K. Promoting bike-and-ride: The Dutch experience. Transportation Research Part A: Policy and Practice. 2007;41(4): 326-338.

[20] Correia G, Viegas JM. Carpooling and carpool clubs: Clarifying concepts and assessing value enhancement possibilities through a Stated Preference web survey in Lisbon, Portugal. Transportation Research Part A: Policy and Practice. 2011;45(2): 81-90.

[21] Szołtysek J. Car-pooling w koncepcji podróży pasażerskiej w miastach. Logistyka, 2008;4: 45-48.

[22] Watson, M. (2012). How theories of practice can inform transition to a decarbonised transport system. Journal of Transport Geography, 24, 488-496.

[23] Mrkajić, V., \& Anguelovski, I. (2016). Planning for sustainable mobility in transition cities: Cycling losses and hopes of revival in Novi Sad, Serbia. Cities, 52, 66-78.

[24] Dell'Olio L, Ibeas A, Cecin P. The quality of services desired by public transport users. Transport Policy 2001;18(1):217-227.

[25] Radnović B, Radenko MM, Radnović V, Ilić M, Lukač D. Marketing Research on Passenger Satisfaction With Public Transport Service in the City of Belgrade. Promet - Traffic \& Transportation. 2015;27(1):47-57

[26] Gajewska T, Grigoroudis E. Importance of logistics services attributes influencing customer satisfaction. Paper presented at: Advanced Logistics and Transport (ICALT) 4th International Conference on. IEEE; 2015 may 20-22; Valenciennes, France. 